Running Title: Taurine supplementation at variable methionine inclusion

\title{
The effect of taurine supplementation to a plant-based diet for barramundi (Lates calcarifer) with varying methionine content.
}

David A. Poppi ${ }^{* 1,2}$, Stephen S. Moore ${ }^{1}$, Brett D. Glencross ${ }^{3}$.

${ }^{1}$ The University of Queensland, Queensland Alliance for Agriculture and Food Innovation, Centre for Animal Science, St. Lucia, QLD 4067, Australia.

${ }^{2}$ CSIRO Agriculture and Food, St. Lucia, QLD 4067, Australia.

${ }^{3}$ Institute of Aquaculture, Stirling University, FK9 4LA Stirling, United Kingdom.

*Corresponding Author: david.poppi@uq.net.au

Postal Address: CSIRO Agriculture and Food, Building 80, Services Road, St. Lucia, QLD 4067, Australia.

Phone: +61 738335527

Keywords: Barramundi, Taurine, Methionine, Nutrient Requirement, Total Sulfur Amino Acids, Restricted Pair Feeding.

This is the peer reviewed version of the following article: Poppi DA, Moore SS, Glencross BD. The effect of taurine supplementation to a plant - based diet for barramundi (Lates calcarifer) with varying methionine content. Aquacult Nutr. 2018; 24:1340-1350, which has been published in final form at https://doi.org/10.1111/anu.12671. This article may be used for non-commercial purposes in accordance With Wiley Terms and Conditions for self-archiving. 


\begin{abstract}
The effect of variable taurine inclusion (Tau) $\left(1 \mathrm{~g} \mathrm{~kg}^{-1} \mathrm{DM}\right.$ to $\left.15 \mathrm{~g} \mathrm{~kg}^{-1} \mathrm{DM}\right)$ in the diet of juvenile barramundi (Lates calcarifer) on growth and nutrient utilisation was investigated at three levels of dietary methionine (Met) supplementation. Diets were fed to juvenile barramundi (starting weight: $26.8 \mathrm{~g}$ ) twice daily under a restricted pair-fed regime for a period of 42 days. No significant effect of dietary Tau supply on growth or nutrient utilisation was observed at any level of Met inclusion. Numerical variations suggested a positive effect of Tau provision at the mid-level of supplementation (6-8 $\left.\mathrm{g} \mathrm{kg}^{-1} \mathrm{DM}\right)$. The best-fit response model (5-SKM), fitted to the percent body weight gain data of fish fed diets with an adequate level of Met, suggested a relatively weak pattern of response $\left(\mathrm{R}^{2}=0.183\right)$ and predicted a Tau requirement of $5.47 \mathrm{~g} \mathrm{~kg}^{-1} \mathrm{DM}(0.96 \% \mathrm{CP})$, similar to that reported for several other species. It was concluded that taurine appears to be conditionally essential to barramundi and should be provided in the diet when sulfur amino acid supply is insufficient to meet biosynthetic demands and that the predicted requirement is likely reasonably accurate for use as a minimum level of inclusion.
\end{abstract}

\title{
1. Introduction
}

Taurine (Tau) is an amino sulphonic acid, possessing a sulfonate group in place of the carboxyl group indicative of the proteinogenic amino acids, nevertheless is often grouped with the sulfur amino acids owing to the fact it is one of the end products of sulfur amino acid metabolism (Hayes, 1976). It is known to be involved in a range of processes important to the health and metabolic functioning of animals including acting as an organic osmolyte, regulating cellular volume and thus osmotic stress and osmoregulation (an important function for marine, and especially euryhaline fish species such as barramundi)(Yancey, 2005). It also plays an important role in nutrient absorption, conjugating with bile acids in the liver to improve absorption of lipids and possibly contributing to cholesterol clearance (Yun et al., 2012). Its antioxidant properties are central in stabilising cellular membranes during periods of disease challenge (Asha and Devadasan, 2013) and it is also thought to regulate mitochondrial protein synthesis (Jong et al., 2012).

Taurine is generally regarded as a "conditionally essential" amino acid in fish, meaning it is required primarily in situations where endogenous production occurs, but at a rate which cannot meet 
demand (Espe et al., 2012; El-Sayed, 2014). In cases such as inadequate supply of precursors (ElSayed, 2014) or where enzymes of the biosynthetic pathway are lacking or have a reduced activity, it may need to be supplemented in the diet. Little attention has been paid in the past to the inclusion of this nutritional component in the diet of carnivorous fish species due to its relative abundance, and that of its precursor amino acids methionine (Met) and cysteine (Cys), in fishmeal, which has traditionally been the major source of protein for formulated diets for these species. The recent trend towards increasing the use of more environmentally and economically sustainable sources of protein such as plant meals, which are largely devoid of Tau and often limiting in Met, has created an impetus for focus on this issue in recent years (Watson et al., 2015). Many of the earlier studies have primarily focused on concluding whether or not Tau is required at all in the diet of the studied species without a quantitative estimation of the level at which maximum gains are made (see review by Salze and Davis, 2015). Estimations of "requirement" for non-essential amino acids can be confounded by the inclusion levels of the amino acid(s) from which they can be synthesised, leading most studies (even those where response to multiple levels of dietary Tau were assessed) to conclude only whether they consider it to be "required" or "not required" in the diet (Kousoulaki et al., 2009; BañuelosVargas et al., 2014). Of those which have offered an estimate of requirement, estimates have varied between $0.2 \%$ of the diet for common dentex (Dentex dentex) (Chatzifotis et al., 2008) and sea bass (Dicentrarchus labrax) (Brotons Martinez et al., 2004) and 1.7\% of the diet for Japanese flounder (Paralichthys olivaceous) (Kim et al., 2005).

A recent study concluded the requirement of juvenile barramundi for total sulfur amino acids (TSAA; Methionine+Cystine) to be $20.2 \mathrm{~g} \mathrm{~kg}^{-1}$ (99\% of maximum response) in a diet with $592 \mathrm{~g} \mathrm{~kg}^{-1}$ CP (3.4\% CP) (Poppi et al., 2017). Given that many fish species have the capacity to synthesize Tau from these sulfur amino acid precursors (Goto et al., 2001; Salze and Davis, 2015), we were interested in whether a proportion of the TSAA requirement estimated in that study was due to a requirement for the production of Tau and, by association, whether the Tau level used in that study was indeed adequate. In particular, we were interested in whether variation of dietary Tau at a level marginally below the TSAA level eliciting maximum growth in that study would significantly affect the growth and nutrient utilisation of similar sized barramundi. In addition, just as variations in dietary Cys content can affect the requirement for Met (Twibell et al., 2000), if the animal has an 
efficient mechanism for synthesizing Tau from Met, then variation in the supply of Met should impact the amount of supplementary Tau required to elicit optimal growth from plant-based diets for carnivorous fish.

The primary aim of the present study was to assess the effect of varying dietary Tau supply on the growth and nutrient utilisation of juvenile barramundi, with a view to determining an optimal level of dietary inclusion in formulated feeds for this species. Additionally, we aimed to define the essentiality of this amino acid and the relationship this has with dietary Met/TSAA supply.

\section{Materials and Methods}

\subsection{Diets}

\subsubsection{Formulation}

A series of five isonitrogenous and isoenergetic diets were formulated (Table 1) to assess the quantitative requirement for dietary Tau by juvenile barramundi. These diets contained varying levels of dietary Tau inclusion between one and $15 \mathrm{~g} \mathrm{~kg}^{-1} \mathrm{DM}$, based around an assumed adequate level of $4 \mathrm{~g}$ $\mathrm{kg}^{-1} \mathrm{DM}$ derived from the proportion of Tau to lysine in the barramundi carcass profile of Glencross et al. (2013) and Glencross (unpublished carcass Tau content data); and with an adequate level of dietary Met/TSAA (13 $\mathrm{g} \mathrm{kg}^{-1}$ DM Met; $18 \mathrm{~g} \mathrm{~kg}^{-1}$ DM TSAA ), according to Poppi et al. (2017). While, in hindsight, this method of estimating Tau adequacy may not be strictly appropriate for a nonproteinogenic amino acid, this level of Tau inclusion is similar to those reported as optimal for several other fish species (Salze and Davis, 2015). The non-essential amino acid glycine replaced the varying amino acid(s) (Tau and/or Met) in order to maintain the total amino acid, crude protein and energy contents of the diets consistent with that done by other authors investigating sulfur amino acid requirements (Simmons et al., 1999; Liao et al., 2014).

Six additional diets were formulated to contain equivalent dietary Tau contents to the lowest $\left(1 \mathrm{~g} \mathrm{~kg}^{-1} \mathrm{DM}\right)$, assumed adequate $\left(4 \mathrm{~g} \mathrm{~kg}^{-1} \mathrm{DM}\right)$ and highest $\left(15 \mathrm{~g} \mathrm{~kg}^{-1} \mathrm{DM}\right)$ diets but with either a deficient $\left(8 \mathrm{~g} \mathrm{~kg}^{-1} \mathrm{DM}\right)$ or excessive $\left(18 \mathrm{~g} \mathrm{~kg}^{-1} \mathrm{DM}\right)$ level of dietary Met, in order to investigate the effect of dietary Met supply on the response to Tau. Post-experiment analyses determined the dietary Tau contents of these additional diet series to be one, six or $12 \mathrm{~g} \mathrm{~kg}^{-1} \mathrm{DM}$. 
All diets were supplemented with a mix of crystalline amino acids to ensure all essential amino acids were provided in excess of requirements according to the ideal protein concept, with reference to lysine and according to the barramundi carcass profile of Glencross et al. (2013) and Glencross (unpublished carcass Tau content data).

Yttrium oxide was included in all diets at a concentration of $1 \mathrm{~g} \mathrm{~kg}^{-1}$ for the purposes of digestibility assessment.

\subsubsection{Diet manufacture}

Diets were prepared, manufactured on a laboratory-scale twin-screw extruder (MPF24; Baker Perkins, Peterborough, UK) and vacuum infused with fish oil according to the methods described in Glencross et al. (2016) to produce a $4 \mathrm{~mm}$ diameter pellet.

\subsection{Fish management and faecal collection}

Experiments were conducted in accordance with the Australian Code of Practice for the Care and Use of Animals for Scientific Purposes, under the approval of the CSIRO Animal Ethics Committee (approval number: A6/2015).

The experiment was undertaken as 11 treatments, with each treatment randomly assigned to triplicate tanks.

\section{[Table 1 here]}

In order to obtain a pooled average weight, forty juvenile hatchery-reared barramundi (Lates calcarifer) were randomly selected from a pooled population and individually weighed to $0.1 \mathrm{~g}$ accuracy. Thirty fish with an average weight of $26.8 \mathrm{~g} \pm 6.7 \mathrm{~g}$ were then randomly allocated to each of the thirty three 1000L tanks. Fish were anaesthetised prior to weighing with AQUI-S $(\sim 0.02 \mathrm{~mL} / \mathrm{L})$ (AQUI-S New Zealand Ltd) before recovering in their allocated tank.

Experimental tanks were provided with $\sim 3 \mathrm{~L} / \mathrm{min}$ flow of continuously aerated marine water ( $\sim 35 \mathrm{PSU}$ ) of $28.9^{\circ} \mathrm{C} \pm 0.2^{\circ} \mathrm{C}$ throughout the experiment. Photoperiod was set at 12:12 (light: dark). 
A restricted pair-fed feeding strategy, as recommended by Glencross et al. (2007), was used to negate any influence of feed intake on the observed response to feed composition variation. For a period of seven days prior to commencing the experiment, consumption of a commercial barramundi diet (4mm Marine Float, Ridley Aquafeed Pty Ltd), fed twice daily to satiety, was monitored in order to establish a satiety feeding rate. Feed intake during this period was observed to be $0.7 \mathrm{~g} \mathrm{fish}^{-1}$ day $^{-1}$ on average.

Based on this, the initial rations were set at $0.6 \mathrm{~g} \mathrm{fish}^{-1} \mathrm{day}^{-1}$ for all tanks. Rations were hand fed to each tank twice daily at 0800 and 1600 , seven days a week. The ration was increased by $0.2 \mathrm{~g}$ fish $^{-1}$ day $^{-1}$ on a weekly basis. Enthusiastic feeding response in all tanks, taken to indicate insufficient ration, prompted increases in the ration of $0.3 \mathrm{~g} \mathrm{fish}^{-1}$ day $^{-1}$ on Day 7 and $0.2 \mathrm{~g}$ fish ${ }^{-1}$ day $^{-1}$ Day 31 and day 32 .

Feed consumption was recorded daily for assessment of feed conversion and feed efficiency ratios. Uneaten feed was removed and an equivalent amount added to the subsequent ration. Consequently, feed intake did not differ between treatments.

All feed remained in cold storage $\left(<4^{\circ} \mathrm{C}\right)$ other than during feeding and weighing.

\subsection{Sample collection}

At the commencement of the experiment, five fish were randomly selected and euthanised by overdose of anaesthetic (AQUI-S) and stored at $-20^{\circ} \mathrm{C}$ until required for baseline proximate analysis. After 42 days, all fish were individually weighed for comparison of growth rate between treatments. At this time, a random sample of five fish from each replicate tank were euthanised by overdose of anaesthetic (AQUI-S) and stored at $-20^{\circ} \mathrm{C}$. Feed was withheld for a period of 24 hours prior to this sampling.

In order to calculate dietary digestible protein and energy contents, faeces were stripped from the fish over a period of six days after a three day rest period subsequent to the conclusion of the growth trial. During this period, all fish were fed their respective diets between 0800 and 1000 with fecal collection undertaken from selected tanks between 1600 and 1800 on the same day. In order to minimise stress and maximise feed intake on the day of collection, fish were stripped on nonconsecutive days. Fecal collection was carried out according to the procedures outlined in Glencross 
(2011). Fish were transferred from their respective tanks by net and placed in a 100L tank containing aerated seawater and a light dose of AQUI-S $(\sim 0.02 \mathrm{~mL} / \mathrm{L})$ and observed until loss of equilibrium occurred, at which point they were removed for stripping. Specific attention was paid to the relaxation of the ventral abdominal muscles of the fish to ensure collection of the faeces occurred before involuntary evacuation. Once removed from the anesthetic tank, faeces were stripped from the distal intestine using gentle abdominal pressure into a pooled plastic specimen jar and frozen at $-20^{\circ} \mathrm{C}$. Contamination of the faeces with urine or mucous was minimised by rinsing of the hands between fish.

\subsection{Chemical and digestibility analyses}

Whole animals were minced, freeze dried and ground prior to analysis. Diets and faecal samples were similarly ground and homogenised and all samples were analysed for dry matter, ash, nitrogen, lipid and gross energy content as described below. Amino acid profiles of the diets were also determined, as well as yttrium contents of diets and faeces.

Sample dry matter contents were calculated by mass change after drying at $105^{\circ} \mathrm{C}$ for $16 \mathrm{~h}$. Gross ash contents were determined gravimetrically following combustion in a muffle furnace at $550^{\circ} \mathrm{C}$ for 16 hours. Crude lipid contents were determined after extraction of sample lipid according to the method of Folch et al. (1957). Total nitrogen content was determined by organic elemental analysis (CHNS-O, Flash 2000, Thermo Scientific, USA) and the sample protein content calculated based on $N$ x 6.25 . Gross energy analysis was undertaken using isoperibolic bomb calorimetry in a Parr 6200 oxygen bomb calorimeter (Par Instrument Company, Moline, IL, USA). Mass detection after reverse-phase ultra high-performance liquid chromatography, using pre-column derivatisation with 6-aminoquinolyl-N-hydroxysuccinimidyl (AQC) was used to determine diet amino acid composition. Analyses were undertaken on a Shimadzu Nexera X2 series UHPLC (Shimadzu Corporation, Kyoto, Japan) coupled with a Shimadzu 8030 Mass Spectrometer. Ground diet samples were prepared and hydrolyzed in $6 \mathrm{~N}$ phenolic $\mathrm{HCl}$ in accordance with the protocol for complex feed samples of Waters Corp. (1996). It is known that Cys is destroyed by acid hydrolysis and methionine is inconsistently oxidized to methionine sulfone (Rutherfurd and Gilani, 2009). Consequently, contents of these amino acids were quantified based on the abundance of cysteic acid and methionine 
sulfone respectively in the samples, following pre-hydrolysis oxidation with performic acid according to a protocol adapted from that of Chavali et al. (2013) (with the exception that $11 \mathrm{~mL}$ glass vials were used and the samples dried by Speedivac vacuum drier).

Feed and faeces were microwave digested in $5 \mathrm{~mL} \mathrm{HNO}_{3}$, based on a modification of EPA method 3051 (EPA, 1994), and yttrium concentrations determined by inductively coupled plasma mass spectrometry (ICP-MS).

Individual nutritional parameter (DM, protein and gross energy) apparent digestibilities $\left(\mathrm{AD}_{\text {Parameter }}\right)$ were calculated by consideration of the difference in ratios of the parameter of interest to yttrium concentration between the diets and faeces using the following formula (Maynard and Loosli, 1969):

$\mathrm{AD}_{\text {Parameter }}=\left[1-\left(\frac{Y_{\text {diet }} \times \text { Parameter }_{\text {faeces }}}{Y_{\text {faeces }} \times \text { Parameter }_{\text {diet }}}\right)\right] \times 100$

Where: $Y_{\text {diet }}$ and $Y_{\text {faces }}$ represent the yttrium content of the diet and faeces, respectively, and Parameter $_{\text {diet }}$ and Parameter $r_{\text {faeces }}$ represent the nutritional parameter of interest (DM, protein or energy) content of the diet and faeces, respectively. Digestible protein and energy contents of the diets were then calculated from these values.

\subsection{Statistical analysis}

The trends of the responses (linear, quadratic or cubic) to variable Tau inclusion at an adequate level of dietary Met was analysed by multiple regression analysis. All parameters of interest within each experiment (Initial and Final Body Weight, \% Body Weight Gain, FCR, Feed Intake, Protein and Energy Retention Efficiencies and final carcass compositions) were also analysed by a One-Way ANOVA with a post hoc comparison of treatment group means by Tukey's honestly significant difference (HSD) multiple range test in order to illustrate the magnitude of the differences.

The effects of both Tau and of Met were analysed by two-way ANOVA. Simultaneous tests for General Linear Hypotheses were undertaken using Tukey's HSD contrasts to elucidate significant differences in response between individual treatments. 
Percentage data was arcsine transformed prior to analyses. All statistical tests were conducted in the R-project statistical environment (R Core Team, 2014). Effects were considered significant at $\mathrm{p}<0.05$.

The response of the fish, in percent body weight gain, to variable dietary Tau at an adequate Met level was analysed using nine nutrient response models (linear and quadratic ascending broken line, four- and five-parameter Saturation Kinetics, three- and four-parameter logistics, a compartmental, a sigmoidal and an exponential model) as described by Poppi et al. (2017). Coefficient of determination $\left(\mathrm{R}^{2}\right)$ and sum of squared errors (SSE) terms were calculated for each of the models according to Pesti et al. (2009). The "best fit" model was determined to be that which resulted in the lowest SSE and highest $\mathrm{R}^{2}$.

A "requirement" for Tau was also calculated and was considered to be the Tau level eliciting 99\% of the maximum response as predicted by the model best fitting the observed percent body weight gain data.

\section{Results}

\subsection{Response to increasing dietary Tau content at an adequate Met level}

Increasing dietary Tau content seemed to have little effect on growth or nutrient utilisation in the studied fish when they were fed diets containing adequate levels of Met (Table 2). A significant effect of treatment on final weight of the fish was observed with fish fed the diet with the lowest dietary Tau content (Diet 1) being significantly smaller than those in either the assumed adequate (Diet 3) or excessive (Diet 5) Tau treatments. This effect was significantly linear with a less significant quadratic effect. No significant effect of treatment on percent body weight gain was observed. This response variable may be a more robust indicator of treatment influence on growth, or lack thereof, given the very small differences in overall weight gain $\left(1.3 \mathrm{~g}\right.$ fish ${ }^{-1}$ maximum) between treatments.

Similarly, dietary treatment had little influence on body composition with ash content being the only variable exhibiting any significant response, decreasing significantly between Diet one and Diet three. 
Of the nine nutrient response models fitted to the data, the best fitting model, the 5-parameter saturation kinetics model (5-SKM), explained $18.3 \%$ of the variation in the percent body weight gain of all replicate tanks fed with diets containing adequate Met and variable Tau (Fig. 1). The Tau requirement predicted by this model was $5.47 \mathrm{~g} \mathrm{~kg}^{-1} \mathrm{DM}(0.96 \% \mathrm{CP})$.

\section{[Table 2 here]}

[Figure 1 here]

\subsection{Response to variable dietary Tau and Met content}

Dietary Met content exerted a greater effect on response than did dietary Tau (Table 3). Both Final Weight and PRE were significantly affected overall by dietary Tau content, however no significant differences were seen within individual dietary Met levels. These responses, however, along with \%BW gain and FCR were highly significantly affected by dietary Met content, with Final Weight, \%BW gain and PRE being significantly lower, and FCR significantly higher, in fish fed the Met deficient diet than those fed the Met adequate and excess diets at both shared Tau levels. ERE was similarly highly significantly affected by dietary Met content with fish fed the Met and Tau deficient diet (Diet 6) retaining significantly less energy than those fish in the Met adequate and excess treatments at the taurine deficient level (Diets 1 and 9).

Carcass crude protein and lipid levels were also deemed to be significantly impacted by dietary Met level only, though no significant differences were seen between diets with the same Tau content. The effect of dietary Tau on carcass ash content was not considered significant by this statistical method.

While not statistically significant, it is notable that at all three levels of dietary Met, \%BW gain peaked numerically at the middle level of Tau (at either 6 or $8 \mathrm{~g} \mathrm{~kg}^{-1}$ ) which may indicate some sort of nutritional adequacy at around this level. 
[Table 3 here]

\section{Discussion}

Taurine is not considered an essential amino acid in the diet of those fish species, such as rainbow trout (Oncorhynchus mykiss) and Nile tilapia (Tilapia niloticus) (Haga et al., 2015), which are able to synthesize it from precursor sulfur amino acids. It has, however, been reported that this biosynthetic capacity is not shared by all species (Yokoyama et al., 2001; Salze and Davis, 2015). In these situations, and where sufficient precursors are not available (such as in unsupplemented plant meal-based diets), Tau may be considered to be conditionally essential and must be provided in the diet (Watson et al., 2014). The capacity of fish to synthesize Tau can be dependent on a number of factors, including feeding habit, dietary protein source, species and size, among other things (ElSayed, 2014). Many marine fish species, for example, have been shown to have a reduced activity of key enzymes involved in the taurine biosynthetic pathways (Goto et al., 2001; Kim et al., 2008), while this activity is generally not limiting in freshwater species (Yokoyama et al., 2001; Wang et al., 2015). However, no biological reason for this separation between environments has been put forward. As barramundi are euryhaline, determination of their biosynthetic capacity may add to clarification of this issue. Often, initial dietary formulations for novel species use amino acid profiles based on that of the animal itself. Indeed, the diets for the current experiment were formulated using the ideal protein concept, with reference to lysine, based on the barramundi carcass amino acid composition published by Glencross et al. (2013) and Glencross (unpublished carcass Tau content data). While this concept often provides reasonably accurate estimates of essential amino acid (EAA) requirements (Mambrini and Kaushik, 1995), it does not hold true for all amino acids. Certain amino acids may be utilised at different rates, depending on their metabolic roles (NRC, 2011), leading some to be underor overestimated by ideal protein (Rollin et al., 2003). This could be especially true for Tau given its role in, for example, conjugating with bile acids in the liver, the requirement for which may be affected by the dietary composition. As well, as Tau is not a proteinogenic amino acid, and thus its proportion in the body is likely both temporally variable (Baskin and Finney, 1981) and not genetically controlled (as protein content is; NRC, 2011), body composition at a specific point in time may not be the ideal basis on which to base dietary Tau requirement. It is necessary, then, to 
determine this figure experimentally. The purpose of this experiment was to investigate the impact of variable dietary Tau content on the growth and nutrient utilisation of juvenile barramundi when fed a diet with a sufficient TSAA content, with the intention of estimating the level at which growth is optimized (a "requirement" level). Additionally, we were interested to know whether varying the dietary TSAA content affected the response to variable taurine which may have suggested whether the animal was in fact synthesizing Tau from these precursors.

At an adequate level of TSAA, changes in dietary Tau from one to $15 \mathrm{~g} \mathrm{~kg}^{-1}$ had no significant effect on growth performance of the fish. This would seem to suggest that Tau is not required to be supplemented in the diet of juvenile barramundi at all when this level of dietary TSAA is supplied and may be an indication that most, if not all, of the Tau required by the fish may have been provided through synthesis from precursor sulfur amino acids (SAA.

The relatively small differences in weight gain between treatments, however, make it difficult to detect significance, especially when natural variations in growth and feeding behavior between fish are taken into account. This lack of divergence in growth may be attributable, in part, to the restricted feeding pair-feeding regime applied. It was decided to follow this method, similar to that used by Glencross et al. (2003) and Enes et al. (2008), in order to negate the impact of feed intake (which can be influenced by several factors unrelated to nutritional adequacy) on physiological response, which is often seen as a confounding factor in satiety fed studies (Glencross et al., 2007) and isolate the effect of variable taurine supply. A negative aspect of this approach, however, is that for the faster growing animals (presumably being those fed at least an "adequate" amount of Tau, assuming Tau positively impacts growth), the feed intake becomes increasingly restrictive with respect to the requirement of the animal for protein and energy, which may have resulted in a greater proportion of the ingested amino acids being catabolized for energetic needs and not deposited in the body. It is possible then that feeding to satiety (as is most common in the fish nutrition literature) might have yielded more significant results. Whether the results using that method would have been more accurate, however, is debatable given that variations in feed intake were identified by El-Sayed (2014) as a possible major factor in the growth stimulation seen in response to taurine supplementation in several studies. Perhaps feeding in proportion to animal body weight would negate this confounding aspect, although the regular weighing required would be impractical and may have its own impacts on feed intake. 
Similarly to the gross growth response, nutrient utilisation was largely unaffected by taurine supplementation, as also reported by Gaylord et al. (2007). A significant main effect of dietary Tau and an interactive effect of dietary Tau and Met was, however, seen on PRE when considered across all levels of dietary Met. This parameter was observed to increase with increasing dietary Tau at a deficient level of Met and peaked numerically at the adequate level of Tau in the excessive Met diet series, suggesting Tau supplementation may improve the efficiency of dietary protein utilization, possibly due to sparing of dietary Met for protein synthesis. This proposition of sparing of Met by Tau may also be supported by the observation that supplementation of taurine effected an apparent downward trend (though not significantly so) in carcass lipid content between the lowest and moderate levels of supplementation at the adequate Met level while carcass crude protein remained relatively unchanged. A similar observation was also made by Espe et al. (2012) and was attributed to a known interaction between lipid deposition and polyamines, the production of which SAdenosylmethionine (SAM) is a donor of aminoisopropyl groups (Brosnan and Brosnan, 2006). Those authors suggested that additional Tau may have spared hepatic Met for SAM synthesis which, in turn, increased production of polyamines.

The response of fish to variable Tau was investigated at a level of TSAA close to the optimal requirement reported in Poppi et al. (2017) (17.1 - 20.2 $\left.\mathrm{g} \mathrm{kg}^{-1} \mathrm{DM}\right)$. The diets were formulated to contain a level of TSAA marginally below the upper end of the requirement range, however, analysed values for both Met and Cys, while consistent across diets, were lower than expected, most likely due to variation in ingredient compositions between that used in our formulation model (based on a database of compositions of previous batches of ingredients used in our lab) and that of the batch used to produce the diets in this study. Nevertheless, the levels were still well within the requirement range and remain relevant to the original objectives. It was decided to use a level close to the asymptotic response, rather than closer to the minimum requirement, in order to assess the contribution of dietary Tau level to the response seen in that previous study. It could have been reasonably assumed that, if a proportion of the TSAA eliciting the maximum response in Poppi et al. (2017) was being used to synthesize Tau, reducing the dietary Tau content at that same Met level should have impacted growth (i.e. indicating the reported TSAA requirement is a Met+Cys+Tau requirement). While this would have been an interesting observation, it was perhaps not the best approach for estimating the true Tau 
requirement independent of the effect of Met. It may have been more accurate to use a dietary Met level marginally limiting or at the lower end of the requirement range as suggested by Salini et al. (2015) for assessing the impact of fatty acid deficiency in this species (barramundi). In this way, the response to dietary treatment could have been separated between that due to the supplementary Tau and the Tau being synthesised from excess SAA.

What was clear in this study was that varying the dietary Met content had a much more significant effect on growth and nutrient utilisation than did Tau inclusion level. The purpose of varying the dietary Met inclusion at common Tau levels was to investigate whether the response to Tau was dependent on the level of Met. This may also serve as an indication of whether Tau is being synthesised at all from Met. It was expected that, if Tau biosynthesis was active in this species, those fish fed the Met deficient diet series, where Met would be limiting to protein synthesis, would exhibit a more significant response to increasing Tau (which may spare Met for protein synthesis), than those fed diets with adequate or excessive levels of Met, where Met supply may be sufficient to cover both the Met and Tau requirements. There was, however, no significant effect of Tau supplementation on growth between those fish fed the deficient and assumed adequate and excessive Tau diets. In this case, as all other essential amino acids (EAA) were provided in the diet well in excess of their requirements, Met would have been, by far, the most limiting amino acid for protein synthesis. It appears, then, that any sparing effect of Tau, even at excessive levels of inclusion, was not enough to make up for this deficiency. It should also be noted that the highest level of Tau inclusion was well in excess of the assumed requirement $\left(4 \mathrm{~g} \mathrm{~kg}^{-1}\right)$. Perhaps, even when precursors are limiting, supplemental Tau is only advantageous up to the point where the requirement is met and does not impact the metabolism of other essential amino acids. In the present study, at the excessive Met level, where Met would clearly not be limiting protein synthesis, the lack of response to increasing Tau may confirm that barramundi can indeed efficiently synthesize Tau from Met, with synthesis possibly fulfilling the requirement for Tau, without the need for supplementation.

The available evidence seems to suggest that Tau is not required by barramundi, at least at this level of dietary TSAA inclusion. Nevertheless nine nutrient response models were applied to the percent body weight gain data of each experimental unit (the average within each tank) in order to estimate the dietary Tau level required to elicit the maximum growth (i.e. a "requirement"). Of these, 
the five-parameter saturation kinetics model (5-SKM) provided the best fit to the data, revealing a relatively weak pattern of response $\left(\mathrm{R}^{2}=0.18\right)$ and predicting a Tau requirement of $5.47 \mathrm{~g} \mathrm{~kg}^{-1} \mathrm{DM}$ $(0.96 \% \mathrm{CP})$. As an aside, when applied to the average percent body weight gain of each treatment (i.e. the average of the three replicate tanks within each treatment, rather than considering each tank individually), however, the 5-SKM explained $90.3 \%$ of the variation in the data, emphasising the importance of data selection when applying statistical models. Using the treatment averages ignores the variation in the data and is, therefore, less accurate, giving false-confidence in prediction outputs of that model (although the two predicted similar Tau requirements) so that based on data from all experimental units (every tank) must be considered to be the more reliable representation. This figure is similar to the recommended beneficial level of supplementation of $5 \mathrm{~g} \mathrm{~kg}^{-1}$ reported for several marine species, including cobia (Rachycentron canadum) (Lunger et al., 2007) and red sea bream (Pagrus major) (Matsunari et al., 2008; Takagi et al., 2010), as well as the freshwater fish rainbow trout (Gaylord et al., 2007), suggesting it may be valid.

Defining a requirement for a non-essential amino acid is difficult as the level of supplementation required to elicit the maximum response would be dependent on the availability of the precursors required for their synthesis. Tau requirement, in particular, may be highly variable due to the range of processes in which it is involved. Fluctuations in salinity, for example, may necessitate the modulation of cellular Tau content, which has been shown to improve the osmotic tolerance of erythrocytes in yellowtail (Seriola quinqueradiata) (Takagi et al., 2006). In addition, it may be problematic to draw conclusions from a model fitted to data which has been shown to not differ significantly between treatments. It is perhaps more accurate to conclude that Tau appears to positively affect growth in this species but that it is not clear the level at which this effect is optimized and that it may not be required to be supplemented in the diet at all if sufficient precursors are provided. In this way, it can be considered to be "conditionally essential" as suggested by various authors (Salze et al., 2011; Espe et al., 2012). Numerical peaks in percent body weight gain at the middle level of Tau supplementation $\left(6-8 \mathrm{~g} \mathrm{~kg}^{-1}\right)$ at all levels of dietary Met, coupled with a significantly positive effect of Tau supplementation on protein retention, when varying Met level was taken into account, supports this assertion and, at least, confirms this level is a good starting point from which to further investigate this topic. 
In order to get a more accurate estimate of the relationship between precursor supply and Tau requirement, it may be useful to conduct a more thorough investigation of the effectiveness of TSAA variation, in particular that of Cys, the major amino acid precursor for Tau synthesis and one which is relatively abundant in terrestrial plant meals, in sparing Tau. In addition, the present experiment was conducted in seawater. As this species is euryhaline and is cultured in freshwater in some countries (Ayson et al., 2013), acclimation of the fish to fresh water would be possible and a re-assessment of the response to Tau supplementation under these conditions may be an interesting avenue of future exploration. Comparison of these results may suggest the contribution of osmoregulatory demands to the overall requirement for Tau supplementation.

\section{Conclusion}

The results of the present study demonstrate that Tau supplementation to plant-based diets may have a positive effect on the growth of juvenile barramundi, however, this effect is diminished by adequate supply of precursor sulfur amino acids. This further supports that this species likely has an efficient mechanism for synthesizing Tau. Additionally, adequate or excessive supply of Tau cannot ameliorate the negative impact of Met deficiency. Further work is required to define the sparing effect of dietary Cys on the Tau requirement and the impact salinity has on this requirement for barramundi.

\section{Acknowledgements}

The authors would like to acknowledge the staff of the CSIRO Bribie Island Aquaculture Centre (BIRC): Mr. Simon Irvin, Ms. Natalie Habilay, Mr. Isaak Kadel and Mr. Joel Slinger for their assistance in the collection of samples and Mr. David Blyth in the preparation of the diets. The assistance in statistical analyses provided by Dr. Yutao Li is also gratefully acknowledged. This research did not receive a specific grant but was funded by the Commonwealth Scientific and Industrial Research Organisation (CSIRO). David Poppi received support through an Australian Government Research Training Program Scholarship. 


\section{References}

Asha, K., Devadasan, K., 2013. Protective effect of taurine on the mitochondria of albino rats induced with fulminant hepatic failure. Biomedicine \& Preventive Nutrition. 3, 279-283.

Ayson, F.G., Seguma, K., Yashiro, R., De Jesus-Ayson, E.G.T., 2013. Nursery and Grow-out Culture of Asian Seabass, Lates calcarifer, in Selected Countries in Southeast Asia. in: Jerry, D.R. (Ed.), Biology and Culture of Asian Seabass Lates Calcarifer. CRC Press, pp. 273-292.

Bañuelos-Vargas, I., López, L.M., Pérez-Jiménez, A., Peres, H., 2014. Effect of fishmeal replacement by soy protein concentrate with taurine supplementation on hepatic intermediary metabolism and antioxidant status of totoaba juveniles (Totoaba macdonaldi). Comparative Biochemistry and Physiology Part B: Biochemistry and Molecular Biology. 170, 18-25.

Baskin, S.I., Finney, C.M., 1981. Factors that Modify the Tissue Concentration or Metabolism of Taurine. in: Schaffer, S.W., Baskin, S.I., Kocsis, J.J. (Eds.), The Effects of Taurine on Excitable Tissues: Proceedings of the 21st Annual A. N. Richards Symposium of the Physiological Society of Philadelphia, Valley Forge, Pennsylvania, April 23-24, 1979. Springer Netherlands, Dordrecht, pp. 411-412.

Brosnan, J.T., Brosnan, M.E., 2006. The sulfur-containing amino acids: an overview. The Journal of nutrition. 136, 1636S-1640S.

Brotons Martinez, J., Chatzifotis, S., Divanach, P., Takeuchi, T., 2004. Effect of dietary taurine supplementation on growth performance and feed selection of sea bass Dicentrarchus labrax fry fed with demand-feeders. Fisheries Science. 70, 74-79.

Chatzifotis, S., Polemitou, I., Divanach, P., Antonopoulou, E., 2008. Effect of dietary taurine supplementation on growth performance and bile salt activated lipase activity of common dentex, Dentex dentex, fed a fish meal/soy protein concentrate-based diet. Aquaculture. 275, 201-208.

Chavali, A., Wheat, T., LeBlanc, G., McMilllan, D., 2013. Complete Amino Acid Analysis of Foods and Feeds. in: Pulkrabová, J., Tomaniová, M., Nielen, M., Hajšlová, J. (Eds.), Poster Session Presented at the 6th International Symposium on Recent Advances in Food Analysis, Prague, Czech Republic. 
El-Sayed, A.F.M., 2014. Is dietary taurine supplementation beneficial for farmed fish and shrimp? A comprehensive review. Reviews in Aquaculture. 6, 241-255.

Enes, P., Panserat, S., Kaushik, S., Oliva-Teles, A., 2008. Growth performance and metabolic utilization of diets with native and waxy maize starch by gilthead sea bream (Sparus aurata) juveniles. Aquaculture. 274, 101-108.

Espe, M., Ruohonen, K., El-Mowafi, A., 2012. Effect of taurine supplementation on the metabolism and body lipid-to-protein ratio in juvenile Atlantic salmon (Salmo salar). Aquaculture Research. 43, 349-360.

Folch, J., Lees, M., Sloane-Stanley, G., 1957. A simple method for the isolation and purification of total lipids from animal tissues. J. biol. Chem. 226, 497-509.

Gaylord, T.G., Barrows, F.T., Teague, A.M., Johansen, K.A., Overturf, K.E., Shepherd, B., 2007. Supplementation of taurine and methionine to all-plant protein diets for rainbow trout (Oncorhynchus mykiss). Aquaculture. 269, 514-524.

Glencross, B., 2011. A comparison of the digestibility of diets and ingredients fed to rainbow trout (Oncorhynchus mykiss) or barramundi (Lates calcarifer) - the potential for inference of digestibility values among species. Aquaculture Nutrition. 17, e207-e215.

Glencross, B., Booth, M., Allan, G., 2007. A feed is only as good as its ingredients-a review of ingredient evaluation strategies for aquaculture feeds. Aquaculture nutrition. 13, 17-34.

Glencross, B., Wade, N., Morton, K., 2013. Lates calcarifer Nutrition and Feeding Practices. in: Jerry, D.R. (Ed.), Biology and Culture of Asian Seabass Lates Calcarifer. CRC Press, pp. 178-228.

Glencross, B., Curnow, J., Hawkins, W., Kissil, G., Peterson, D., 2003. Evaluation of the feed value of a transgenic strain of the narrow-leaf lupin (Lupinus angustifolius) in the diet of the marine fish, Pagrus auratus. Aquaculture Nutrition. 9, 197-206.

Glencross, B., Blyth, D., Irvin, S., Bourne, N., Campet, M., Boisot, P., Wade, N.M., 2016. An evaluation of the complete replacement of both fishmeal and fish oil in diets for juvenile Asian seabass, Lates calcarifer. Aquaculture. 451, 298-309.

Goto, T., Tiba, K., Sakurada, Y., Takagi, S., 2001. Determination of hepatic cysteinesulfinate decarboxylase activity in fish by means of OPA-prelabeling and reverse-phase highperformance liquid chromatographic separation. Fisheries science. 67, 553-555. 
Haga, Y., Kondo, H., Kumagai, A., Satoh, N., Hirono, I., Satoh, S., 2015. Isolation, molecular characterization of cysteine sulfinic acid decarboxylase (CSD) of red sea bream Pagrus major and yellowtail Seriola quinqueradiata and expression analysis of CSD from several marine fish species. Aquaculture. 449, 8-17.

Hayes, K., 1976. A review on the biological function of taurine. Nutrition reviews. 34, 161-165.

Jong, C.J., Azuma, J., Schaffer, S., 2012. Mechanism underlying the antioxidant activity of taurine: prevention of mitochondrial oxidant production. Amino acids. 42, 2223-2232.

Kim, S.-K., Takeuchi, T., Yokoyama, M., Murata, Y., Kaneniwa, M., Sakakura, Y., 2005. Effect of dietary taurine levels on growth and feeding behavior of juvenile Japanese flounder Paralichthys olivaceus. Aquaculture. 250, 765-774.

Kim, S.-K., Matsunari, H., Takeuchi, T., Yokoyama, M., Furuita, H., Murata, Y., Goto, T., 2008. Comparison of taurine biosynthesis ability between juveniles of Japanese flounder and common carp. Amino acids. 35, 161-168.

Kousoulaki, K., Albrektsen, S., Langmyhr, E., Olsen, H.J., Campbell, P., Aksnes, A., 2009. The water soluble fraction in fish meal (stickwater) stimulates growth in Atlantic salmon (Salmo salar L.) given high plant protein diets. Aquaculture. 289, 74-83.

Liao, Y., Ren, M., Liu, B., Sun, S., Cui, H., Xie, J., Zhou, Q., Pan, L., Chen, R., Ge, X., 2014. Dietary methionine requirement of juvenile blunt snout bream (Megalobrama amblycephala) at a constant dietary cystine level. Aquaculture Nutrition. 20, 741-752.

Lunger, A.N., McLean, E., Gaylord, T.G., Kuhn, D., Craig, S.R., 2007. Taurine supplementation to alternative dietary proteins used in fish meal replacement enhances growth of juvenile cobia (Rachycentron canadum). Aquaculture. 271, 401-410.

Mambrini, M., Kaushik, S., 1995. Indispensable amino acid requirements of fish: correspondence between quantitative data and amino acid profiles of tissue proteins. Journal of Applied Ichthyology. 11, 240-247.

Matsunari, H., Yamamoto, T., Kim, S.K., Goto, T., Takeuchi, T., 2008. Optimum dietary taurine level in casein-based diet for juvenile red sea bream Pagrus major. Fisheries science. 74, 347-353.

Maynard, L.A., Loosli, J.K., 1969. Animal nutrition 6th ed. McGraw-Hill, New York. 
NRC, 2011. Nutrient requirements of fish and shrimp. The National Academies Press Washington,

DC.

Pesti, G., Vedenov, D., Cason, J., Billard, L., 2009. A comparison of methods to estimate nutritional requirements from experimental data. British poultry science. 50, 16-32.

Poppi, D.A., Moore, S.S., Glencross, B.D., 2017. Redefining the requirement for total sulfur amino acids in the diet of barramundi (Lates calcarifer) including assessment of the cystine replacement value. Aquaculture. 471, 213-222.

R Core Team, 2014. R: A language and environment for statistical computing. R Foundation for Statistical Computing, Vienna, Austria. URL http://www.R-project.org/.

Rollin, X., Mambrini, M., Abboudi, T., Larondelle, Y., Kaushik, S.J., 2003. The optimum dietary indispensable amino acid pattern for growing Atlantic salmon (Salmo salar L.) fry. British Journal of Nutrition. 90, 865-876.

Rutherfurd, S.M., Gilani, G.S., 2009. Amino acid analysis. Current Protocols in Protein Science, 11.19. 11-11.19. 37.

Salini, M.J., Turchini, G.M., Wade, N.M., Glencross, B.D., 2015. Rapid effects of essential fatty acid deficiency on growth and development parameters and transcription of key fatty acid metabolism genes in juvenile barramundi (Lates calcarifer). British Journal of Nutrition. 114, 1784-1796.

Salze, G., Craig, S., Smith, B., Smith, E., McLean, E., 2011. Morphological development of larval cobia Rachycentron canadum and the influence of dietary taurine supplementation. Journal of Fish Biology. 78, 1470-1491.

Salze, G.P., Davis, D.A., 2015. Taurine: a critical nutrient for future fish feeds. Aquaculture. 437, 215-229.

Simmons, L., Moccia, R., Bureau, D., Sivak, J., Herbert, K., 1999. Dietary methionine requirement of juvenile Arctic charr Salvelinus alpinus (L.). Aquaculture Nutrition. 5, 93-100.

Takagi, S., Murata, H., Goto, T., Hayashi, M., Hatate, H., Endo, M., Yamashita, H., Ukawa, M., 2006. Hemolytic suppression roles of taurine in yellowtail Seriola quinqueradiata fed non-fishmeal diet based on soybean protein. Fisheries Science. 72, 546-555. 
Takagi, S., Murata, H., Goto, T., Hatate, H., Endo, M., Yamashita, H., Miyatake, H., Ukawa, M., 2010. Neccessity of dietary taurine supplementation for preventing green liver symptom and improving growth performance in yearling red sea bream Pagrus major fed nonfishmeal diets based on soy protein concentrate. Fisheries Science. 76, 119-130.

Twibell, R.G., Wilson, K.A., Brown, P.B., 2000. Dietary sulfur amino acid requirement of juvenile yellow perch fed the maximum cystine replacement value for methionine. The Journal of nutrition. 130, 612-616.

US Environmental Protection Agency (EPA), 1994. Method 3051: Micro-wave Assisted Acid Digestion of Sediments, Sludges, Soils and Oils. US Environmental Protection Agency, Office of Solid Waste, US Government Printing Office, Washington, DC.

Wang, X., He, G., Mai, K., Xu, W., Zhou, H., 2015. Ontogenetic taurine biosynthesis ability in rainbow trout (Oncorhynchus mykiss). Comparative Biochemistry and Physiology Part B: Biochemistry and Molecular Biology. 185, 10-15.

Waters Corp., 1996. Analyzing feed hydrolysate samples using the AccQ•Tag method. Milford, MA: Waters Corporation.

Watson, A.M., Barrows, F.T., Place, A.R., 2014. Effects of graded taurine levels on juvenile cobia. North American Journal of Aquaculture. 76, 190-200.

Watson, A.M., Barrows, F.T., Allen, R., 2015. The Importance of Taurine and n-3 Fatty Acids in Cobia, Rachycentron canadum, Nutrition. Bull. Fish. Res. Agen. No. 40, 51-59.

Yancey, P.H., 2005. Organic osmolytes as compatible, metabolic and counteracting cytoprotectants in high osmolarity and other stresses. Journal of Experimental Biology. 208, 2819-2830.

Yokoyama, M., Takeuchi, T., Park, G., Nakazoe, J., 2001. Hepatic cysteinesulphinate decarboxylase activity in fish. Aquaculture Research. 32, 216-220.

Yun, B., Ai, Q., Mai, K., Xu, W., Qi, G., Luo, Y., 2012. Synergistic effects of dietary cholesterol and taurine on growth performance and cholesterol metabolism in juvenile turbot (Scophthalmus maximus L.) fed high plant protein diets. Aquaculture. 324, 85-91. 
Table 1. Formulations and analysed compositions of the experimental diets.

\begin{tabular}{|c|c|c|c|c|c|c|c|c|c|c|c|}
\hline & $\begin{array}{c}\text { Diet } \\
1 \\
\end{array}$ & $\begin{array}{c}\text { Diet } \\
2 \\
\end{array}$ & $\begin{array}{c}\text { Diet } \\
\mathbf{3} \\
\end{array}$ & $\begin{array}{c}\text { Diet } \\
\mathbf{4}\end{array}$ & $\begin{array}{c}\text { Diet } \\
5 \\
\end{array}$ & $\begin{array}{c}\text { Diet } \\
6 \\
\end{array}$ & $\begin{array}{c}\text { Diet } \\
7 \\
\end{array}$ & $\begin{array}{c}\text { Diet } \\
8 \\
\end{array}$ & $\begin{array}{c}\text { Diet } \\
9\end{array}$ & $\begin{array}{c}\text { Diet } \\
10 \\
\end{array}$ & $\begin{array}{c}\text { Diet } \\
11 \\
\end{array}$ \\
\hline \multicolumn{12}{|l|}{ Ingredients $\left(\mathrm{g} \mathrm{kg}^{-1}\right)$} \\
\hline Fishmeal $^{1}$ & 150 & 150 & 150 & 150 & 150 & 150 & 150 & 150 & 150 & 150 & 150 \\
\hline SPC & 490 & 490 & 490 & 490 & 490 & 490 & 490 & 490 & 490 & 490 & 490 \\
\hline Fish oil $^{2}$ & 100 & 100 & 100 & 100 & 100 & 100 & 100 & 100 & 100 & 100 & 100 \\
\hline Cellulose & 67 & 67 & 67 & 67 & 67 & 67 & 67 & 67 & 67 & 67 & 67 \\
\hline Pregel Starch & 53 & 53 & 53 & 53 & 53 & 53 & 53 & 53 & 53 & 53 & 53 \\
\hline $\mathrm{CaHPO}_{4}$ & 20 & 20 & 20 & 20 & 20 & 20 & 20 & 20 & 20 & 20 & 20 \\
\hline Vit. and Min. Premix ${ }^{3}$ & 6 & 6 & 6 & 6 & 6 & 6 & 6 & 6 & 6 & 6 & 6 \\
\hline Choline chloride ${ }^{4}$ & 1 & 1 & 1 & 1 & 1 & 1 & 1 & 1 & 1 & 1 & 1 \\
\hline $\operatorname{Marker}\left(\mathrm{Y}_{2} \mathrm{O}_{3}\right)$ & 1 & 1 & 1 & 1 & 1 & 1 & 1 & 1 & 1 & 1 & 1 \\
\hline DL-Met & 6.5 & 6.5 & 6.5 & 6.5 & 6.5 & 0 & 0 & 0 & 13 & 13 & 13 \\
\hline L-Tau & 0 & 3 & 8 & 13 & 19 & 0 & 8 & 19 & 0 & 8 & 19 \\
\hline L-Gly & 25.5 & 22.5 & 17.5 & 12.5 & 6.5 & 32 & 24 & 13 & 19 & 11 & 0 \\
\hline EAA Premix $^{5}$ & 80 & 80 & 80 & 80 & 80 & 80 & 80 & 80 & 80 & 80 & 80 \\
\hline \multicolumn{12}{|c|}{ Composition as determined ( $\mathrm{g} \mathrm{kg}^{-1} \mathrm{DM}$ unless otherwise stated) } \\
\hline Dry matter $\left(\mathrm{g} \mathrm{kg}^{-1}\right.$ as is) & 971 & 972 & 971 & 971 & 968 & 974 & 966 & 968 & 970 & 968 & 976 \\
\hline Crude Protein & 582 & 569 & 569 & 558 & 558 & 580 & 567 & 559 & 557 & 556 & 553 \\
\hline Digestible Protein & 484 & 437 & 474 & 448 & 446 & 466 & 480 & 453 & 427 & 465 & 422 \\
\hline Lipid & 116 & 115 & 114 & 118 & 117 & 119 & 120 & 120 & 114 & 120 & 121 \\
\hline Ash & 75.6 & 74.5 & 74.5 & 74.9 & 74.3 & 74.5 & 74.1 & 74.6 & 74.9 & 74.8 & 74.7 \\
\hline Gross Energy (MJ kg-1 DM) & 21.9 & 21.6 & 21.6 & 21.7 & 21.6 & 21.8 & 22.0 & 22.0 & 22.0 & 21.8 & 21.8 \\
\hline $\mathrm{DE}\left(\mathrm{MJ} \mathrm{kg}^{-1} \mathrm{DM}\right)$ & 16.9 & 16.1 & 16.6 & 16.2 & 16.1 & 16.0 & 17.1 & 16.6 & 16.1 & 16.6 & 15.9 \\
\hline
\end{tabular}

EAAs

\begin{tabular}{lccccccccccc} 
Arg & 40 & 39 & 39 & 38 & 38 & 37 & 37 & 37 & 42 & 40 & 39 \\
His & 10 & 12 & 11 & 11 & 10 & 11 & 12 & 11 & 11 & 11 & 13 \\
Ile & 26 & 28 & 27 & 27 & 27 & 27 & 26 & 27 & 28 & 29 & 28 \\
Leu & 42 & 44 & 44 & 45 & 46 & 47 & 47 & 47 & 48 & 49 & 49 \\
Lys & 37 & 38 & 38 & 38 & 36 & 33 & 33 & 35 & 36 & 36 & 35 \\
Met & 13 & 13 & 13 & 13 & 13 & 8 & 8 & 8 & 18 & 18 & 18 \\
Cys & 5 & 5 & 5 & 5 & 5 & 5 & 5 & 5 & 5 & 5 & 5 \\
Phe & 28 & 30 & 29 & 29 & 28 & 28 & 27 & 28 & 28 & 29 & 29 \\
Thr & 28 & 28 & 28 & 28 & 28 & 28 & 28 & 28 & 28 & 29 & 29 \\
Val & 32 & 33 & 33 & 33 & 33 & 33 & 32 & 33 & 33 & 34 & 34 \\
Tau & 1 & 4 & 8 & 12 & 15 & 1 & 6 & 12 & 1 & 6 & 12 \\
\hline
\end{tabular}

${ }^{1}$ Fishmeal: Chilean anchovy meal, Ridley Aquafeeds, Narangba, QLD, Australia.

${ }^{2}$ Fish (anchovy) oil: Ridley Aquafeeds, Narangba, QLD, Australia.

${ }^{3}$ Vitamin and mineral premix includes (IU/kg or g/kg of premix): retinol, $2.5 \mathrm{MIU}$; cholecalciferol, $0.25 \mathrm{MIU} ; \alpha$-tocopherol,16.7g; Vitamin $\mathrm{K} 3,1.7 \mathrm{~g}$; thiamin, 2.5g; riboflavin, 4.2g; niacin, 25g; pantothenic acid, 8.3g; pyridoxine, 2.0g; folate, 0.8g; Vitamin B12, 0.005g; Biotin, 0.17g; Vitamin C, 75g; Inositol, 58.3g; Ethoxyquin, 20.8g; Copper, 2.5g; Ferrous iron, 10.0g; Magnesium, 16.6g; Manganese, 15.0g; Zinc, $25.0 \mathrm{~g}$.

${ }^{4}$ Choline chloride $70 \%$ corn cob

${ }^{5}$ Essential amino acid premix consisting of $\left(\mathrm{g} \mathrm{kg}^{-1}\right.$ of premix): L-Isoleucine, 75.0g; L-Valine, 125.0g; L-Leucine, 187.5g; L-Phenylalanine, 87.5g; L-Threonine, 150.0g; L-Lysine, $187.5 \mathrm{~g}$; L-Arginine, $187.5 \mathrm{~g}$ 
Table 2. Response of juvenile barramundi to variable dietary taurine content at an adequate dietary methionine level $\left(13 \mathrm{~g} \mathrm{~kg}^{-1}\right)^{1}$.

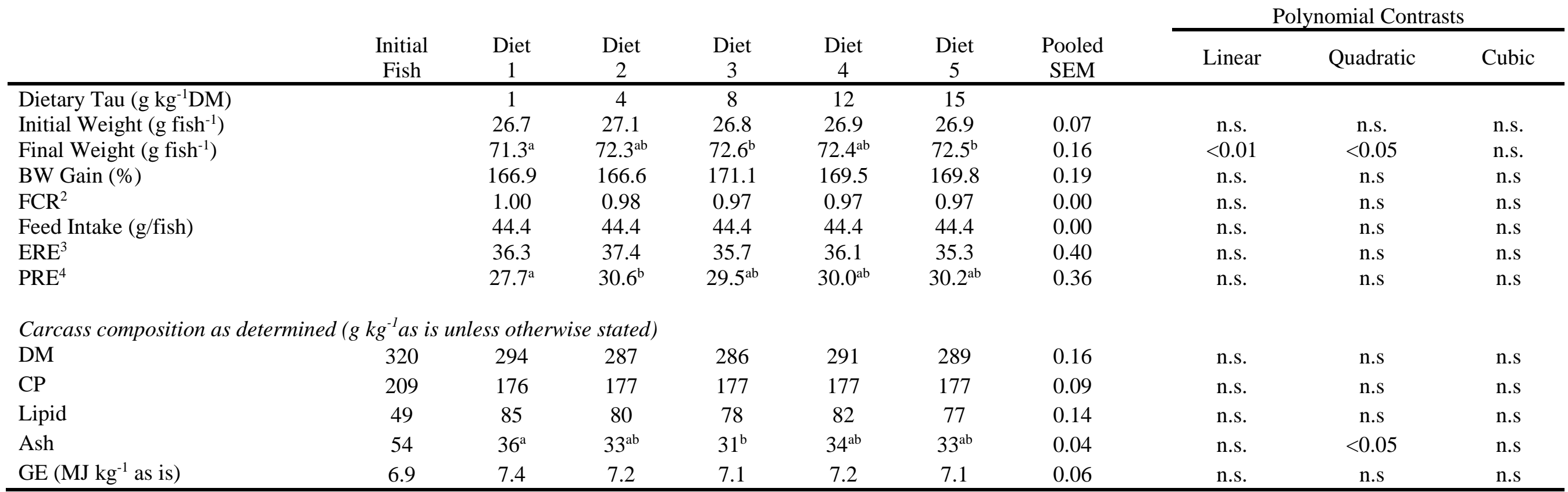

${ }^{1}$ Values with differing superscripts are significantly different ( $\left.p>0.05\right)$; Absence of superscripts denotes values which are not significantly different ( $<<0.05$ ).

${ }^{2}$ FCR: feed conversion ratio (g dry feed/g wet weight gain)

${ }^{3}$ ERE: energy retention efficiency $=\mathrm{MJ}$ energy gain $* 100 / \mathrm{MJ}$ energy consumed

${ }^{4} \mathrm{PRE}$ : protein retention efficiency $=\mathrm{g}$ protein gain $* 100 / \mathrm{g}$ protein consumed 
Table 3. Response of juvenile barramundi to variable taurine content at three levels of dietary methionine.

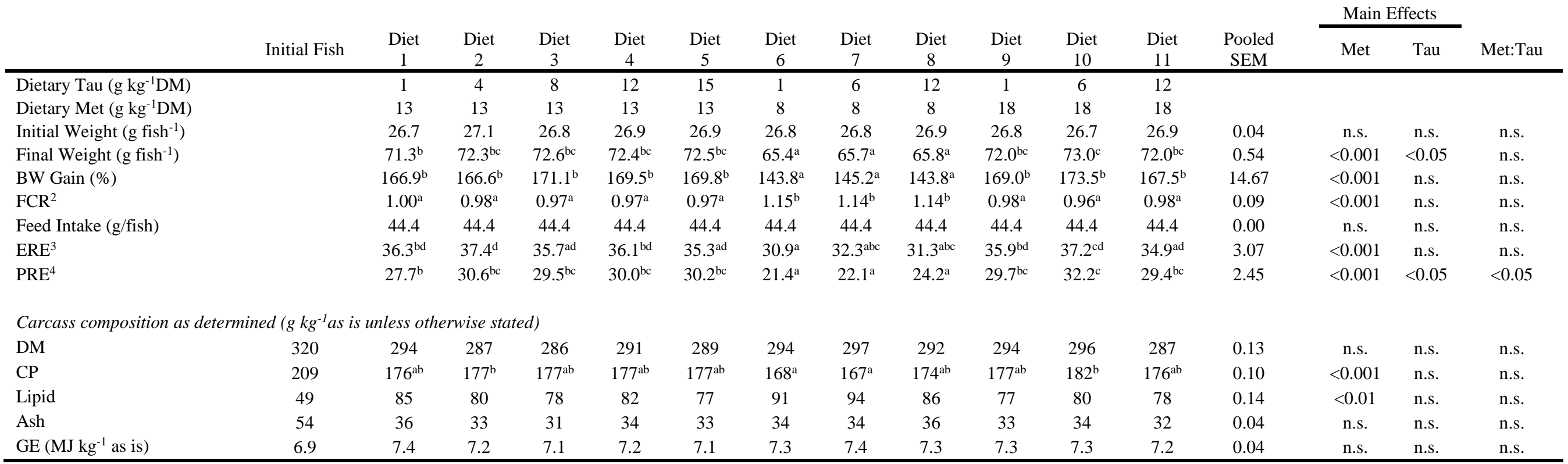

\footnotetext{
${ }^{1}$ Values with differing superscripts are significantly different

${ }^{2}$ FCR: feed conversion ratio (g dry feed/g wet weight gain)

${ }^{3}$ ERE: energy retention efficiency $=$ MJ energy gain $* 100 / \mathrm{MJ}$ energy consumed

${ }^{4}$ PRE: protein retention efficiency $=\mathrm{g}$ protein gain $* 100 / \mathrm{g}$ protein consumed
}

different ( $p>0.05)$; Absence of superscripts denotes values which are not significantly different $(p<0.05)$ 


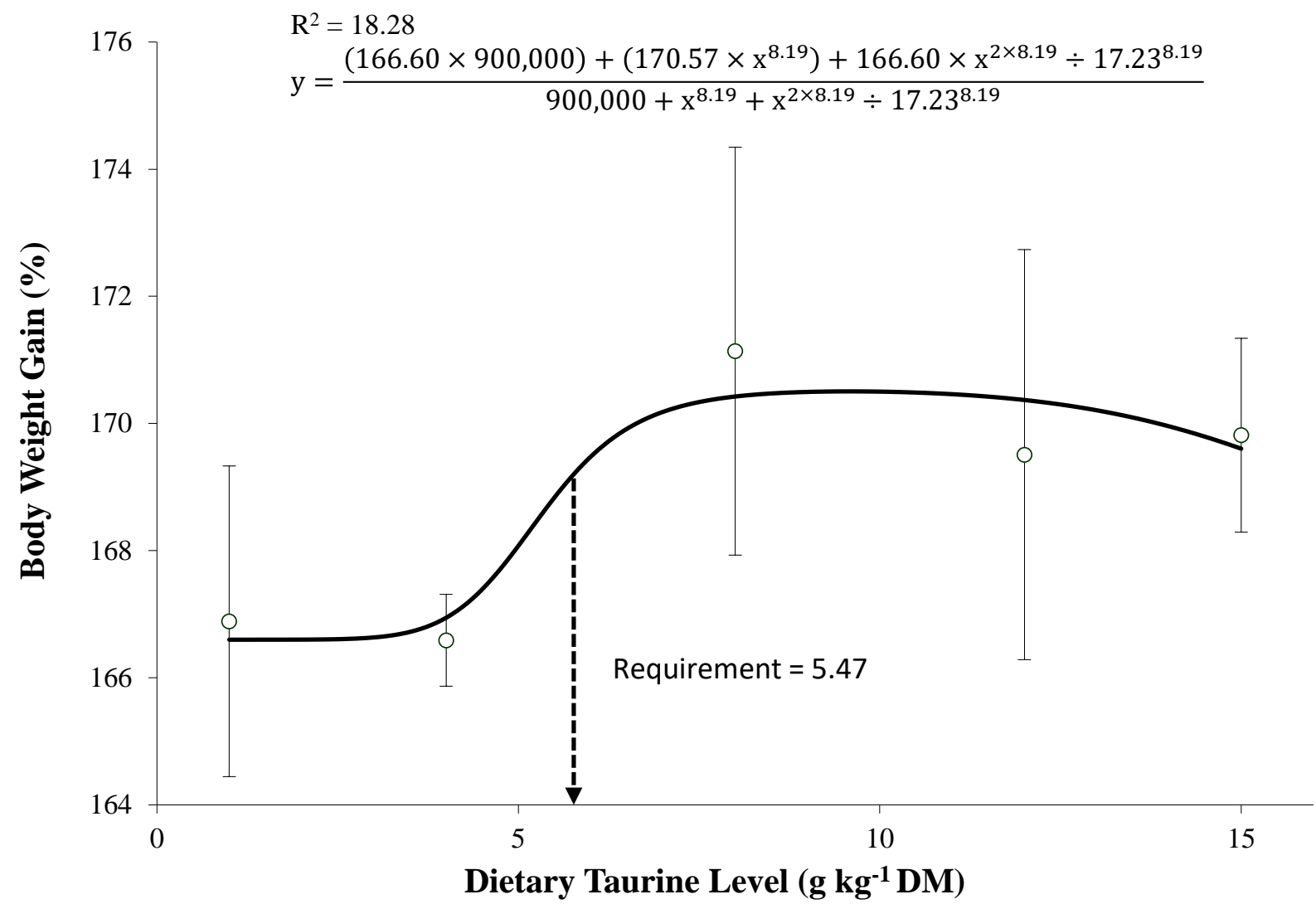

Figure 1. Percent body weight gain $( \pm$ S.E.M.) (mean initial weight $=26.8 \mathrm{~g})$ of juvenile barramundi with taurine requirement predicted by the five-parameter saturation kinetics model fitted to the average of each replicate tank. 